This document is the Accepted Manuscript version of a Published Work that appeared in final form in Inorganic Chemistry, copyright (c) American Chemical Society after peer review and technical editing by the publisher. To access the final edited and published work see:

https://dx.doi.org/10.1021/acs. inorgchem.5b00598. 


\title{
Design and Synthesis of a Non Innocent Multitopic Catechol and Pyridine Mixed Ligand: Nanoscale Polymers and Valence Tautomerism
}

\author{
Mireia Guardingo, ${ }^{\dagger \ddagger}$ Felix Busqué, ${ }^{\S}$ Fernando Novio $^{\dagger \ddagger *}$ and Daniel Ruiz-Molina ${ }^{\dagger \ddagger}$ \\ ${ }^{\dagger}$ ICN2- Institut Catala de Nanociencia I Nanotecnologia, ICN2 Building, Campus UAB, o8193-Bellaterra, Spain \\ ${ }^{\ddagger}$ CSIC-Consejo superior de Investigaciones Científicas, ICN2 Building, Campus UAB o8193-Bellaterra, Spain \\ ${ }^{\S}$ Chemistry Department, Universitat Autònoma de Barcelona, Campus UAB, o8193-Bellaterra, Spain \\ KEYWORDS. Coordination polymer, nanoparticles, valence tautomerism, redox-active ligand, multitopic ligand.
}

Supporting Information Placeholder

\begin{abstract}
The design and synthesis of a new redox-active ligand combining catechol and pyridine units have allowed the obtaining of cobalt-based nanoscale coordination polymer particles on a single-step exhibiting a switchable valence tautomeric behavior and thermal hysteresis. The combination of polymerizing capabilities with redox-active responses in a unique ligand leads to the formation of nanoparticles exhibiting a gradual valence tautomeric interconversion in the $35-370 \mathrm{~K}$ temperature range. Using one single ligand to obtain these nanoparticles facilitates possible nanostructuration methodologies
\end{abstract}

\section{INTRODUCTION}

Some transition metal complexes bearing redox-active ligands can interconvert between two electronically labile states with different net magnetic moments and optical properties. Both isomers can exist in solution as well as in the solid state and interconvert reversibly by an intramolecular oneelectron transfer between the metal ion and the redox-active ligand in response to different external perturbations, such as temperature, ${ }^{2}$ pressure, ${ }^{3}$ irradiation $^{4}$ and more recently $\mathrm{pH} .{ }^{5}$ Complexes of this family, termed as Valence Tautomers (VT), have been proposed as potential building blocks to obtain molecular switching devices, where the ultimate goal is to manipulate information at the molecular level, sensors or display devices. ${ }^{6}$

Most of the VT complexes thus far reported are monomeric ${ }^{7}$ and dimeric ${ }^{8}$ cobalt complexes containing quinone or quinone-type ligands. They are "noninnocent" electroactive ligands that may interconvert between the semiquinone SQand catecholate $\mathrm{Cat}^{2-}$ forms in response to an external stimulus (e.g. temperature). However, the potential application of these systems has been limited by the lack of thermal hysteresis, a necessary prerequisite for having memory effects. Indeed, even though hysteresis in a few monomeric ${ }^{9}$ and dimeric $^{10}$ VT complexes has been reported and associated with their supramolecular packing, ${ }^{11}$ crystal engineering did not provide the basic tools for the proper design of molecular systems with hysteresis. To overcome this limitation, some authors focused their efforts towards the design of VT polymers where the constitutive building blocks are mutually interacting through covalent bonds. The schematic representation of the different approaches so far followed for the obtaining of VT polymers is shown in Figure 1. Within the framework of the first approach (see Fig. 1a), one dimension$\mathrm{al}^{12}$ and two-dimensional coordination polymers ${ }^{13}$ containing cobalt-o-quinone complex units are linked by multitopic pyridyl or pyrazol ligands. While the catechol ligand ensures the switchable behavior through the thermally-induced intramolecular electron transfer with the cobalt ion, the nonactive multitopic bridging ligand acts as a polymerizing agent, being crucial in the formation of the polymeric structures. Pierpont et al. followed this approach to establish the photomechanical polymer $[\mathrm{Co}(\mathrm{pyz})(3,6-\mathrm{DBQ}) 2]_{\mathrm{n}} \cdot{ }^{14}$ This coordination polymer exhibited a temperature-induced tautomeric interconversion in the solid state and a parallel mechanical process associated to variations on the methalcatechol bond lengths. More recently, three novel polymeric complexes with different bidentate-bridging pyridine ligands were synthesized and their VT behavior studied. ${ }^{15}$ Similarly, a series of 1-D polymer structures ranging from amorphous spherical nanoparticles to crystals with several different morphologies ${ }^{16}$ have also been systematically synthesized by controlling experimental parameters such as temperature, reagent concentration or solvent nature. The experimental results indicated that the degree of crystallinity and the crystalline phase critically determine the VT process, independent of the morphology and/or dimensions of the crystals. Worth to mention, relevant hysteresis effects were not reported in any of the previous examples.

The second approach (see Fig. 1b) consists in the use of a bisbidentate catechol-based ligand as a polymerizing agent and the use of an innocent counter ligand to complete the coordination sphere. The last one is required to achieve the proper balance between the frontier orbitals of the catechol and the metal ion involved in the electron transfer. Following this approach, Schultz, Dei et al., have reported VT coordination polymers ${ }^{17}$ and the required cooperative properties that lead to thermal hysteresis. Small hysteresis width (between 5-13 $\mathrm{K}$ ) was found even though the transition could be classified 
a)
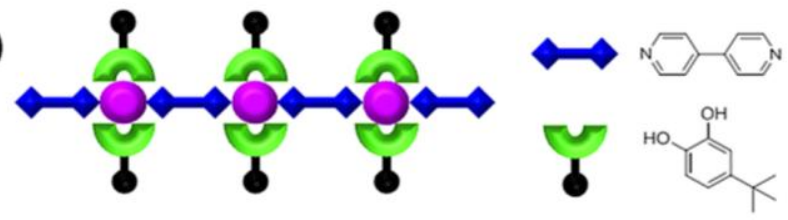

b)
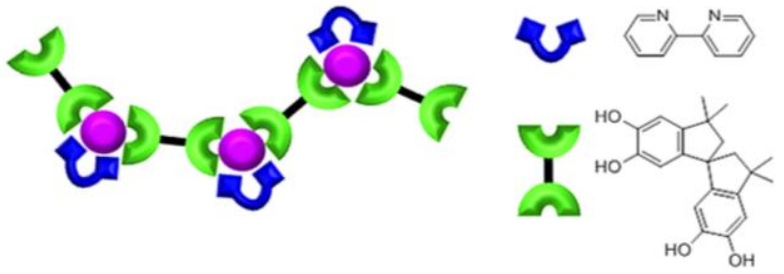

c)

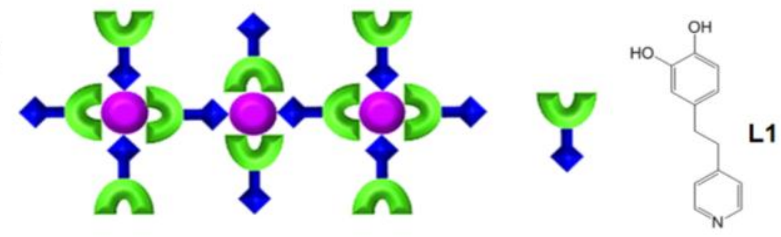

Figure 1. Schematic representation of the different approaches so far followed for the formation of VT coordination polymers: a) combination of catechol ligands with pyridil/pyrazol ligands; b) bisbidentate catechol and bypiridine counterligands; c) catechol and pyridine moieties presents in the same ligand. Cobalt metal ion is represented by a pink sphere.

as gradual, ${ }^{18}$ which was associated to the existence of a cooperativity between the cobalt centres. ${ }^{19}$

Herein we have envisioned a third approach for the obtaining of coordination polymers with VT based on the use of a sole multitopic ligand that associates both polymerizing capabilities with redox-active responses (see Fig. 1c). For this we have designed the new ligand $\mathbf{L} \mathbf{1}$ combining a catechol and a pyridine unit within a single element. A related pyridine derivative catechol ligand designed to behave as a fluorescent chemosensor for wide-range $\mathrm{pH}$ detection has already been described, but no examples of coordination complexes were reported due to the high steric hindrance of the ligand. ${ }^{20}$ In this case, reaction of the single ligand L1 with a cobalt salt and its posterior fast precipitation process was successful and afforded the formation of nanoscale coordination polymers particles (Co-CPPs). Moreover, the new polymer has been found to exhibit VT and hysteresis effects. Therefore, Li not only combines both redox-active and polymerizing capabilities but also allows for the proper balance of localized metal and quinone orbital energies required for the intramolecular electron transfer in VT.

\section{EXPERIMENTAL SECTION}

Commercially available reagents were used as received. The solvents were dried by distillation over the appropriate drying agents. All reactions were performed avoiding moisture by standard procedures and under nitrogen atmosphere and monitored by analytical thin-layer chromatography (TLC) using silica gel 6o F254 pre-coated aluminum plates (0.25 $\mathrm{mm}$ thickness). Flash column chromatography was performed using silica gel 6o $\AA$, particle size $35-70 \mu \mathrm{m}$ (230-40o mesh). Final ligand $\mathbf{L} 1$ as well as all the synthetic intermedi- ates involved is pure within the sensibilities of their ${ }^{1} \mathrm{H}$ - and ${ }^{13} \mathrm{C}$-NMR spectra.

2.1. Synthesis of ligand Catechol-Pyridine (L1). Ligand L1 was obtained following a three-step synthetic methodology shown in Scheme 1 and described below.

2.1.1. Synthesis of $Z$ - and $E$-4-(2-(pyridin-4yl)ethenyl)benzene-1,2-dibenzyloxy (3): To a suspension of $\mathrm{K}_{2} \mathrm{CO}_{3}(0.522 \mathrm{~g}, 3.77 \mathrm{mmol})$ in dry $\mathrm{CH}_{2} \mathrm{Cl}_{2}$ (4 mL) was added a small amount of 18-crown-6-ether and 1 (0.527 g, $0.816 \mathrm{mmol})$ under nitrogen atmosphere. To the resulting mixture a solution of aldehyde $2(70,0.652 \mathrm{mmol})$ in dry $\mathrm{CH}_{2} \mathrm{Cl}_{2}(2 \mathrm{~mL})$ was added and the mixture was refluxed under nitrogen for 24 hours. After that time, the solvent was evaporated and the crude was purified by flash column chromatography (hexane/ EtOAc 80:20) to provide the separation of the 1:1 of $Z$ - and $E$-(3) fractions $(219 \mathrm{mg}, 0.557 \mathrm{mmol}$, $68 \%$ yield) as a colorless oil ( $Z$-isomer) and white solid ( $E$ isomer) after solvent evaporation.

Caracterization of Z-(3): ${ }^{1} \mathrm{H}-\mathrm{NMR}\left(400 \mathrm{MHz}, \mathrm{CDCl}_{3}\right)$ : $\delta 8.55$ (s, 2H: H-11), 7.50- 7.29 (m, 12H), $7.19(\mathrm{~d}, J=17.1 \mathrm{~Hz}, 1 \mathrm{H}), 7.16$ $(\mathrm{s}, 1 \mathrm{H}), 7.07(\mathrm{dd}, J=8.3,1.9 \mathrm{~Hz}, 1 \mathrm{H}), 6.94(\mathrm{~d}, J=8.3 \mathrm{~Hz}, 1 \mathrm{H})$, $6.81(\mathrm{~d}, J=16.2 \mathrm{~Hz}, 1 \mathrm{H}), 5.22(\mathrm{~s}, 2 \mathrm{H}), 5.20(\mathrm{~s}, 2 \mathrm{H}) ;{ }^{13} \mathrm{C}-\mathrm{NMR}$ $\left(100.6 \mathrm{MHz}, \mathrm{CDCl}_{3}\right): \delta$ 150.2, 149.9, 149.2, 145.0, 137.2, 137.1, 133.0, 129.9, 128.7, 128.7, 128.1, 128.0, 127.5, 127.4, 124.4, 121.5, $120.8,114.9,113.4,71.6,71.3$.

Caracterization of E-(3): ${ }^{1} \mathrm{H}-\mathrm{NMR}\left(400 \mathrm{MHz}, \mathrm{CDCl}_{3}\right): \delta 8.40$ $(\mathrm{d}, J=4.2 \mathrm{~Hz}, 2 \mathrm{H}), 7.44-7.16(\mathrm{~m}, 1 \mathrm{OH}), 7.06(\mathrm{~d}, J=5.6 \mathrm{~Hz}$, $2 \mathrm{H}), 6.76(\mathrm{~m}, 2 \mathrm{H}), 6.70(\mathrm{dd}, J=8.3,1.8 \mathrm{~Hz}, 1 \mathrm{H}), 6.58(\mathrm{~d}, J=$ $12.2 \mathrm{~Hz}, 1 \mathrm{H}), 6.32(\mathrm{~d}, J=12.2 \mathrm{~Hz}, 1 \mathrm{H}), 5.09(\mathrm{~s}, 2 \mathrm{H}), 4.88(\mathrm{~s}$, ${ }_{2 \mathrm{H}}$ ); ${ }^{13} \mathrm{C}-\mathrm{NMR}\left(100.6 \mathrm{MHz}, \mathrm{CDCl}_{3}\right): 149.8,148.8,148.6,145.5$, $137.1,137.0,133.6,129.4,128.5,127.9,127.8,127.3,127.1,126.3$, 123.6, 122.6, 115.3, 114.6, 71.2, 71.1.

IR-ATR: $v\left(\mathrm{~cm}^{-1}\right)=3065,3027,2970,2920,2856,1590,1511$, 1267, 1229, 967, 810, 731, 693; HRMS (ESI+) m/z: calcd for $\mathrm{C}_{27} \mathrm{H}_{23} \mathrm{NO}_{2}, 394,1802[\mathrm{M}+\mathrm{H}]^{+}$; found: 394,1807; Mp 126-130 ${ }^{\circ} \mathrm{C}$ (EtOAc).

2.1.2. Synthesis of 4-(2-(pyridinium-4-yl)ethyl)benzene1,2-diol chloride (4): A 1:1 mixture of $(Z)-3$ and $(E)-3 \quad(439$ $\mathrm{mg}, 1.11 \mathrm{mmol}$ ) was dissolved in $10 \mathrm{ml}$ of THF. Then, ammonium formate $(391 \mathrm{mg}, 6.2 \mathrm{mmol})$ and $\mathrm{Pd} / \mathrm{C}(10 \%, 111 \mathrm{mg})$ where added to the mixture and it was refluxed for 4 hours. The suspension was then filtered over a Celite ${ }^{\circledast}$ pad and a few drops of $\mathrm{HCl}(35 \%)$ where added, resulting in the precipitation of compound 4 as a white solid that was filtrated and rinsed with THF (213 mg, o.848 mmol, 82\% yield). ${ }^{1} \mathrm{H}-\mathrm{NMR}$ (40o MHz, DMSO): $\delta 8.79(\mathrm{~d}, J=6.6 \mathrm{~Hz}, 2 \mathrm{H}), 7.88(\mathrm{~d}, J=6.5$ $\mathrm{Hz}, 2 \mathrm{H}), 6.63(\mathrm{~d}, J=8.0 \mathrm{~Hz}, \mathrm{1H}), 6.59(\mathrm{~d}, J=2.0 \mathrm{~Hz}, 1 \mathrm{H}), 6.43$ $(\mathrm{dd}, J=8.0,2.0 \mathrm{~Hz}, 1 \mathrm{H}), 3.11(\mathrm{t}, J=7.7 \mathrm{~Hz}, 2 \mathrm{H}), 2.81(\mathrm{t}, J=7.7$ $\mathrm{Hz}, 2 \mathrm{H}) ;{ }^{13} \mathrm{C}-\mathrm{NMR}$ (100.6 MHz, DMSO): $\delta$ 162.34 (C-9), 145.1, 143.6, 141.0, 130.6, 127.0, 119.0, 115.9, 115.5, 36.9, 34.4; IR-ATR: $v$ $\left(\mathrm{cm}^{-1}\right)=3336,3197,2690,1633,1610,1528,1503,1202,811$; HRMS (ESI+) $\mathrm{m} / \mathrm{z}$ : calcd for $\mathrm{C}_{13} \mathrm{H}_{14} \mathrm{NO}_{2}, 216,1019[\mathrm{M}+\mathrm{H}]^{+}$; found: 216,1028; Mp 176-180 으 (THF).

2.1.3. Synthesis of 4-(2-(pyridin-4-yl)ethyl)benzene-1,2diol (L1): To a suspension of compound 4 (20.4 mg, 0.081 $\mathrm{mmol})$ in THF was added $\mathrm{NaHCO}_{3}(9.1 \mathrm{mg}, 0.108 \mathrm{mmol})$ and a few drops of water and the mixture was stirred at room temperature under nitrogen for 10 minutes. Then the solvent was evaporated and compound L1 was obtained as a pale orange solid (17 mg, 85\% yield) ${ }^{1} \mathrm{H}-\mathrm{NMR}$ (40o $\mathrm{MHz}, \mathrm{MeOD}$ ): $\delta 8.35(\mathrm{~d}, J=5.7 \mathrm{~Hz}, 2 \mathrm{H}), 7.20(\mathrm{~d}, J=6.1 \mathrm{~Hz}, 2 \mathrm{H}), 6.65(\mathrm{~d}, J=$ 8.o Hz, $1 \mathrm{H}), 6.58(\mathrm{~d}, J=2.0 \mathrm{~Hz}, 1 \mathrm{H}), 6.45(\mathrm{dd}, J=8.0,2.0 \mathrm{~Hz}$, $1 \mathrm{H}), 2.90(\mathrm{t}, J=7.4 \mathrm{~Hz}, 2 \mathrm{H}), 2.78(\mathrm{t}, J=7.7 \mathrm{~Hz}, 2 \mathrm{H}) ;{ }^{13} \mathrm{C}-\mathrm{NMR}$ 
(100.6 MHz, MeOD): $\delta$ 153.9, 149.6, 146.1, 144.6, 133.6, 125.8, 120.8, 116.6, 116.3, 38.4, 36.9; IR-ATR: $v\left(\mathrm{~cm}^{-1}\right)=3028,2923$, 2853, 1602, 1527, 1486, 1250, 805, 643, 586, 503; Anal. Calcd (\%) for $\mathrm{C}_{13} \mathrm{H}_{13} \mathrm{NO}_{2}$ : C, 72.54; $\mathrm{H}, 6.09 ; \mathrm{N}, 6.51$. Found: $\mathrm{C}, 72.68$; $\mathrm{H}, 6.26$; $\mathrm{N}, 6.37$; HRMS (ESI+) $\mathrm{m} / \mathrm{z}$ : calcd for $\mathrm{C}_{13} \mathrm{H}_{14} \mathrm{NO}_{2}$, 216,1019 [M+H] $]^{+}$; found: 216,1025; Mp 170-174 ${ }^{\circ} \mathrm{C}$.

2.2. Synthesis of Cobalt-based coordination polymer particles (Co-CPPs). An aqueous solution $(4 \mathrm{~mL})$ of $\mathrm{Co}\left(\mathrm{CH}_{3} \mathrm{COO}\right)_{2} \cdot 4 \mathrm{H}_{2} \mathrm{O}(121.4 \mathrm{mg}$, $0.50 \mathrm{mmol})$ were added dropwise to a solution of ligand $\mathbf{L r}(216.1 \mathrm{mg}, 1 \mathrm{mmol})$ in EtOH (2O $\mathrm{mL}$ ). A black precipitate formed immediately. After $30 \mathrm{~min}-$ utes of reaction time the precipitate was centrifuged and washed several times with water and $\mathrm{EtOH}$, and dried under vacuum. The resulting solid product obtained in $70 \%$ yield. SEM analysis showed the spherical morphology (mean size: $109 \pm 12 \mathrm{~nm}$ ), and XRD measurements indicate the amorphous nature of the particles. IR-ATR: $v(\mathrm{~cm}-1)=3350,2957,2924$, 2856, 1597,1482, 1277, 1222, 1184,1112, 1068, 821, 620, 533; Anal. Calcd for $\mathrm{C}_{26} \mathrm{H}_{22} \mathrm{O}_{4} \mathrm{CoN}_{2}$ : C,64.34; $\mathrm{H}, 4.57 ; \mathrm{N}, 5.77$. Found: $\mathrm{C}$, $64.79 ; \mathrm{H}, 4.66 ; \mathrm{N}, 5.83$.

2.3. Physicochemical characterization. $\mathrm{H}-\mathrm{NMR}$ spectra were recorded on Bruker DPX250 (250 MHz), DPX 360 (360 $\mathrm{MHz}$ ) and $\mathrm{ARX}_{400}(400 \mathrm{MHz})$ spectrometers. Proton chemical shifts are reported in ppm $(\delta)\left(\mathrm{CDCl}_{3}, \delta 7.26\right.$ or $\mathrm{CD}_{3} \mathrm{OD}, \delta$ 3.31). ${ }^{13} \mathrm{C}$-NMR spectra were recorded on Bruker DPX 360 (9o $\mathrm{MHz}$ ) spectrometers with complete proton decoupling. Carbon chemical shifts are reported in ppm $(\delta)\left(\mathrm{CDCl}_{3}, \delta\right.$ 77.0 or $\mathrm{CD}_{3} \mathrm{OD}, \delta$ 49.o). The IR-ATR spectra have been recorded using a Tensor 27 (Bruker) spectrophotometer. The melting points (MP) have been determined using a Reichert kofler block and have not been corrected. Size distribution of the nanoparticles was measured by DLS, using the Zetasizer Nano 3600 instrument (Malvern Instruments, UK). Note: the diameter measured by DLS is the hydrodynamic diameter. All samples were diluted to obtain an adequate nanoparticle concentration. The data reported are mean values for each sample, which were measured in quadruplicate. The UV-VIS spectra were recorded using a Cary 4000 spectrophotometer and a $1 \mathrm{~cm}$ path length quartz cuvette. The baseline was corrected using a blank sample of pure solvent. Powder XRD spectra were recorded at room temperature on a highresolution texture diffractometer (PANalytical X'Pert PRO MRD) equipped with a Co-K $\alpha$ radiation source $(\lambda=1.7903 \AA)$ and operating in reflection mode. The solid samples were placed in an amorphous silicon oxide flat plate and measured directly. SEM images were performed on a scanning electron microscope (FEI Quanta 650 FEG) at acceleration voltages between $2-5 \mathrm{kV}$. Aluminium was used as support. The samples were prepared by drop casting of the corresponding dispersion on aluminum tape followed by evaporation of the solvent under room conditions. Before analysis, the samples were metalized with a thin layer of gold by using a sputter coater (Emitech K550). Energy-dispersive X-Ray sperctroscopy (EDX) analysis were performed using a Quanta 650 FEG microscope equiped with and Inca 250 SSD XMaxzo detector Peltier cooled with $20 \mathrm{~mm}^{2}$ active area and $129 \mathrm{eV}$ resolution. Variable-temperature magnetic characterization was done in a Quantum Design MPMS XL SQUID on the 35$370 \mathrm{~K}$ temperature range operating at a magnetic field strength of $0.1 \mathrm{~T}$. Raman spectra were acquired at different temperatures using a Dilor triplemate spectrograph (180o $1 / \mathrm{mm}$ grating, $100 \mathrm{~lm}$ entrance slit, $1 \mathrm{~cm}^{-1}$ spectral resolution) coupled to a Princeton Instruments CCD detector. The 647.1 $\mathrm{nm}$ line of a $\mathrm{Kr}^{+}$laser (Coherent RadiationInnova) was used as an excitation source with laser power output of $10 \mathrm{~mW}$.

\section{RESULTS AND DISCUSSION}

Synthesis of ligand $\mathrm{Lr}$ and polymerization reaction. Ligand L1 was obtained following a synthetic strategy already reported in our group (Scheme 1). ${ }^{21}$ The first step consists of a Wittig reaction between the previously described phosphorane derivative of compound (1) and 4pyridinecarboxaldehyde (2) to obtain a (1:1) mixture of $Z$ - and E-4-(2-(pyridin-4-yl)ethenyl)benzene-1,2-dibenzyloxy (3) in $68 \%$ yield. This mixture of olefins was hydrogenated, using ammonium formate under palladium catalyst, with concomitant deprotection of the hydroxyl groups. Subsequent addition of concentrated $\mathrm{HCl}$ led to the precipitation of 4 with $82 \%$ overall yield in the three last reactions. Finally, compound 4 was neutralized to obtain the desired ligand L1 that contains the two functional groups (catechol and pyridine) required. Afterwards, nanoscale coordination polymer particles Co-CPPs were obtained by mixing an aqueous solution of cobalt acetate with an ethanolic solution containing two equivalents of $\mathbf{L} \mathbf{1}$ under magnetic stirring. The precipitate formed by in situ polymerization and fast precipitate was collected after 30 minutes, washed several times with water and $\mathrm{EtOH}$, and dried under vacuum resulting in the formation of spherical particles as previously reported. ${ }^{22}$ CPPs exhibit average diameters between 60 and $130 \mathrm{~nm}$ (mean size $110 \mathrm{~nm}$ ), as found by scanning electron microscopy (SEM) (see Fig. 2b) and confirmed by Dynamic Light Scattering (DLS) (see Supporting Information, S1). Moreover, nanoparticle diameters could be controlled by regulating the stirring rate (see Supporting Information, S2) or modifying the synthetic approach. For instance, larger nanoparticles (average diameter between $400 \mathrm{~nm}$ and $1 \mu \mathrm{m}$ ) were obtained by slow diffusion of the cobalt aqueous solution into an alcoholic solution of the ligand L1, without stirring (see Fig. 2a).

Characterization. X-ray powder diffraction of the different batches obtained showed that the particles are amorphous materials preventing a detailed analysis of the structural connectivity (see Supporting information, S3). However, the infrared spectra of the obtained particles corroborate the coordination of the metal centre as revealed by the displacement of the main bands attributed to the $\mathrm{C}-\mathrm{O}$ stretching of the catecholate mode $\left(1280-1250 \mathrm{~cm}^{-1}\right.$ range),
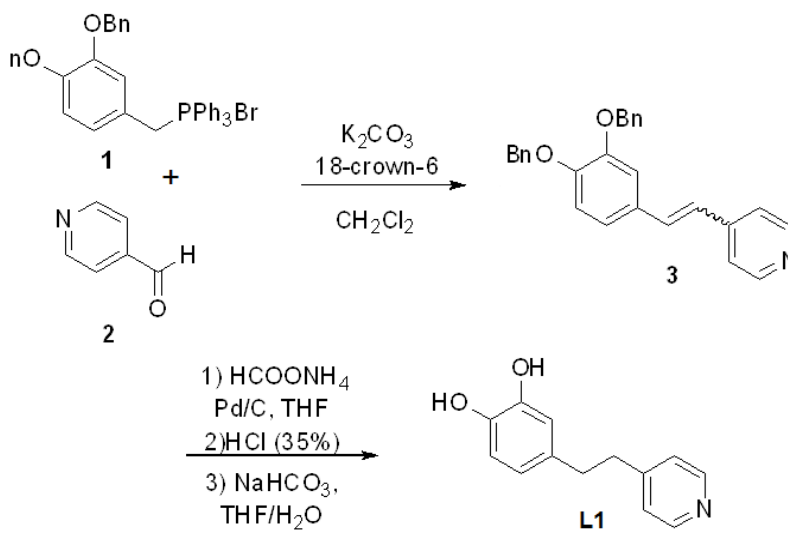

Scheme 1. Synthesis of the ligand L1 
those corresponding to the $\mathrm{C}=\mathrm{C} / \mathrm{C}-\mathrm{N}$ stretching modes (1530$\left.1400 \mathrm{~cm}^{-1}\right)$, the bands in the $900-750 \mathrm{~cm}^{-1}$ range attributed to the $\mathrm{C}-\mathrm{H}$ bend in the aromatic ring, and those in the 700-50o $\mathrm{cm}^{-1}$ region corresponding to $\mathrm{Co}-\mathrm{O}$ and $\mathrm{Co}-\mathrm{N}$ vibrations. (see Supporting Information, $\mathrm{S}_{4}$ ). Energy-Dispersive X-ray Spectroscopy (EDX) and elemental analysis also confirmed that this material contains cobalt, carbon, oxygen, and nitrogen in ratios that are consistent with the proposed polymeric structure (see Supporting Information, $\mathrm{S}_{5}$ ). The thermogravimetric analysis (TGA) performed under $\mathrm{N}_{2}$ atmosphere indicates a good stability up to $175^{\circ} \mathrm{C}$ with only a small weight loss around $5 \%$ at temperatures higher that $75^{\circ} \mathrm{C}$, tentatively assigned to the removal of entrapped solvent (water or most likely ethanol) within the nanoparticles. From $175^{\circ} \mathrm{C}$ to $325^{\circ} \mathrm{C}$ a gradual weight loss attributed to the loss of L1 molecules is observed, whereupon a definitive and drastic thermal decomposition of the material takes place up to $400^{\circ} \mathrm{C}$ (see Supporting Information, S6).

Valence tautomerism. Figure 3 shows the temperature dependent magnetic susceptibility of Co-CPPs in the 35-370 $\mathrm{K}$ temperature range. At the highest temperature of $370 \mathrm{~K}$
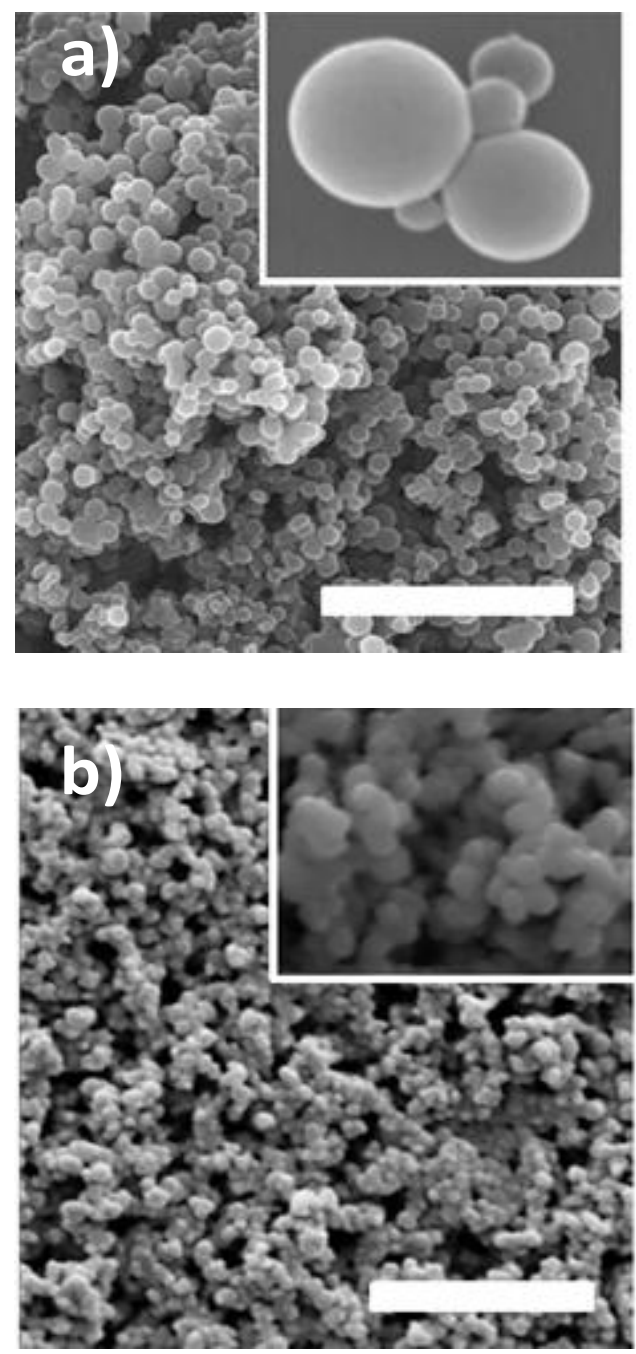

Figure 2. SEM images showing the morphology of Co-CPPs obtained by using different experimental procedures: a) spherical micro-size particles obtained by a diffusion process (bar $=10 \mu \mathrm{m}$ ) and b) nanoparticles obtained under magnetic stirring (bar $=2 \mu \mathrm{m})$.

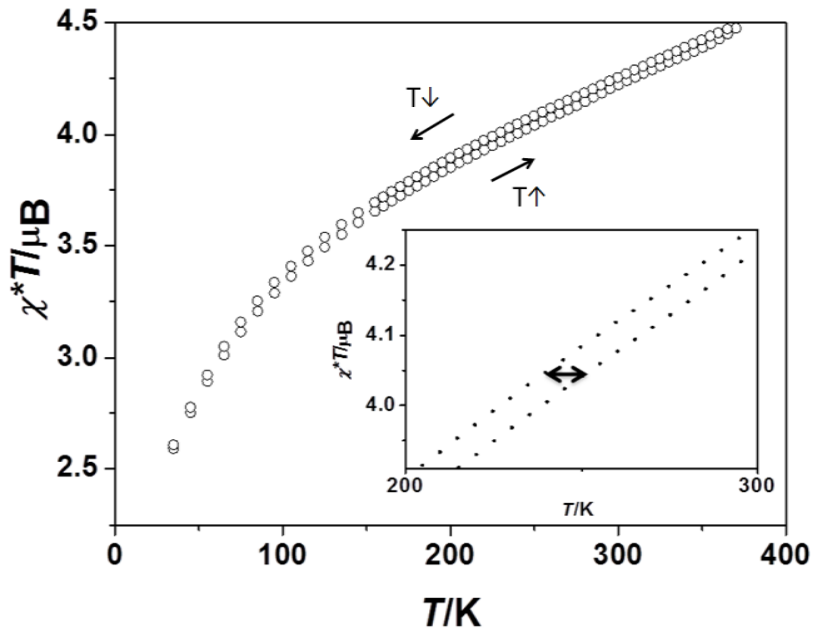

Figure 3. Variable temperature magnetization measurements in the 35-370 K temperature range. Inset: difference in the measured $\mu_{\text {eff }}$ between when heating (bottom line) and cooling (upper line) processes. The arrow in the inset figure evidences the maximum width of thermal hysteresis, $c a .12 \mathrm{~K}$ at $250 \mathrm{~K}$.

the resulting experimental $\mu_{\text {eff }}$ value of $4.4 \mu_{\mathrm{B}}$ is close to the theoretical values expected for a $S=3 / 2+2^{*} 1 / 2$ species with an unquenched orbital contribution $\left(4.6 \mu_{\mathrm{B}}\right)$. Upon cooling, the $\mu_{\text {eff }}$ value monotonically decreases down to $2.6 \mu_{\mathrm{B}}$ at $35 \mathrm{~K}$. A fit a line through the lowest temperature points finally determines an y-intercept around $1.90 \mu_{\mathrm{B}}$, close to the $1.73 \mu_{\mathrm{B}}$ theoretical value for a $\mathrm{S}=1 / 2$ system $\mathrm{Co}(\mathrm{III})$ ground state. On the other side, the gradual interconversion, which is commonly observed in non-crystalline phases and tautomeric coordination polymers, ${ }^{23}$ could be tentatively attributed to the interconversion from the $h s-\mathrm{Co}(\mathrm{II})$ isomer to the $l s-$ $\mathrm{Co}(\mathrm{III})$ isomer together with spin-orbit coupling effects ${ }^{24}$ or the possible presence of an additional structural transition. ${ }^{25}$ Moreover, though less probable, since the actual magnetic structure is not at all known the possibility of a ferromagnetic (Hund's) ground state could not be discarded at this stage. UV-Vis spectroscopy of a dispersion of Co-CPPs in toluene at two different temperatures also confirmed the VT interconversion (see Supporting Information, $\mathrm{S}_{7}$ ). In both spectra bands at $590 \mathrm{~nm}$, characteristic of $l s-\mathrm{Co}(\mathrm{III})$ isomer, and $740 \mathrm{~nm}$ associated to the $h s-\mathrm{Co}(\mathrm{II})$ isomer were observed. ${ }^{14,16,26}$ As the temperature is increased, the intensity of the band at $590 \mathrm{~nm}$ decreases while the band at $740 \mathrm{~nm}$ becomes more intense, in agreement with the existence of VT equilibrium. Moreover, this process is fully reversible over different cycles.

In addition, studies at different temperature were performed using Raman spectrometry to check changes associated with VT processes between 80-373 K (see Supporting Information, S8). Thus, an increasing of signals assigned to intraligand catecholate vibrations, either $\mathrm{C}-\mathrm{C}$ stretching, $\mathrm{v}(\mathrm{C}-\mathrm{C})$, between $1300-1590 \mathrm{~cm}^{-1}$, or $\mathrm{C}-\mathrm{H}$ deformation, $\delta(\mathrm{C}-\mathrm{H})$, at 1190 $\mathrm{cm}^{-1}$ were observed as the temperature was decreased. ${ }^{27} \mathrm{In}$ the Iow-wavenumber region of the spectrum, the peaks between $600-700 \mathrm{~cm}^{-1}$ belong to a symmetric Co-O stretching vibration.

The existence of VT on the Co-CPPs nanoparticles is not only important for their implications in future molecular electronic devices but also for the structural characterization of the material. Indeed, even though the amorphous nature 
of Co-CPPs nanoparticles precludes any accurate structural characterization by classical diffraction techniques, the occurrence of VT corroborates the expected [Co(nitrogen)(quinone)] composition required to ensure a proper energy balance between the antibonding orbital (eg orbital) of the metal ion and the frontier orbitals of catechol ligands for the intramolecular electron transfer to take place. Another important feature of these nanoparticles is the observation of small hysteresis effects (see Inset in Fig. 3); when the nanoparticles are subjected to thermal cycling over the whole temperature range studied, the curves associated to the increase and decrease of the temperature differ by almost 12 K. Such hysteresis is reproducible over different cycles discarding any influence of small composition variations. Moreover, no dependence with the sweeping rate was found discarding a spin frustration mechanism as its origin.

\section{CONCLUSIONS}

In summary, we have designed and synthesized the new bifunctional ligand L1 that combines both polymerizing capabilities with redox-active responses by covalently linking catechol and pyridine units. The coordination of L1 upon reaction with cobalt ions and its subsequent polymerization and precipitation leads to the formation of nanoparticles a few hundred nanometers width exhibiting a gradual VT interconversion in the $35-370 \mathrm{~K}$ temperature range. An important feature of these nanoparticles is the observation of small hysteresis effect that can be related to the cooperative effect between valence tautomeric units induced by the catechol-pyridyl ligand. The midpoints of the cooling and heating curves differ by almost $12 \mathrm{~K}$. Such hysteresis is similar to the one obtained in a previous work by using bis-catecholate ligands (approach 2 of Figure 1) ${ }^{17,18}$ whereas no hysteresis has been found for coordination polymers containing cobalt-oquinone complex units linked by multitopic pyridyl or pyrazol ligands (approach 1 of Figure 1). This fact suggests the need for the catechol to be involved in the polymerization process to induce the hysteresis effect. Using one single ligand to obtain these nanoparticles could enable possible nanostructuration methodologies

\section{ASSOCIATED CONTENT}

\section{Supporting Information}

Contents of material supplied as Supporting Information includes dynamic light scattering, calorimetric studies, powder X-ray diffraction, energy-dispersive X-ray spectroscopy, ATR-IR and UV-vis spectroscopy and scanning electron microscopy images. This material is available free of charge via the Internet at http://pubs.acs.org.

\section{AUTHOR INFORMATION}

Dr. Fernando Novio, fnovio@cinz.es

\section{Author Contributions.}

The manuscript was written through contributions of all authors. All authors have given approval to the final version of the manuscript. In addition, M. Guardingo has synthesized ligand L1. F. Novio has synthesized and characterized the nanoparticles. F. Novio, D. Ruiz-Molina and F. Busqué supervised the project and coordinated the preparation of the manuscript.

\section{Funding Sources}

Ministerio de Ciencia e Innovación (MICINN) through projects MAT2012-38318-Co3-02, MAT2012-38319-Co2-01 and CTQ2010-15380 and FEDER funds. The authors declare no competing financial interests.

\section{ACKNOWLEDGMENT}

This work was supported ICN2 acknowledges support from the Severo Ochoa Program (MINECO, Grant SEV-2013o295).F.N. thanks the Ministerio de Ciencia e Innovación (MICINN) for a JdC fellowship. M. G. thanks the Consejo Superioir de Investigaciones Científicas (CSIC) for a JAE fellowship. The authors also thank ECOSTBio Cost Action and Dr. G. Molnar and Prof. A. Bousseksou for Raman measurements and very helpful discussions.

\section{REFERENCES}

(1) (a) Evangelio, E.; Ruiz-Molina, D. Eur. J. Inorg. Chem., 2005, 2957-2971. (b) Gütlich, P.; Dei, A. Angew. Chem. Int. Ed. Engl., 1997, 36, 2734-2736.

(2) Tezgerevska, T.; Alley, K. G.; Boskovic, C. Coord. Chem. Rev. 2014, 268, 23-40.

(3) Roux, C.; Adams, D. M.; Itié, J. P.; Polian, A.; Hendrickson, D. N.; Verdaguer, M. Inorg. Chem., 1996, 35, 2846-2852.

(4) Sato, O.; Cui, A.; Matsuda, R.; Tao, J.; Hayami, S. Acc. Chem. Res., 2007, 40, 361-369.

(5) Nador, F.; Novio, F.; Ruiz-Molina, D. Chem. Commun., 2014, 50, 14570-14572.

(6) (a) P González - Monje, F Novio, D Ruiz - Molina, Chem. Eur. J. 2015, 21, 1-7 (b) Dei, A.; Gatteschi, D. Angew. Chem., Int. Ed. 2011, 50, 11852-11858. (c) Sato, O.; Cui, A.; Matsuda, R.; Tao, J.; Hayami, S. Acc. Chem. Res. 2007, 40, 361-369. (d) Hendrickson, D. N.; Pierpont, C. G. Top. Curr. Chem. 2004, 234, 63-95. (e) Gütlich, P.; Garcia, Y.; Goodwin, H. A. Chem. Soc. Rev. 200o, 29, 419-427.

(7) (a) Mulyama, Y.; Poneti, G.; Moubaraki, B.; Murray, K. S.; Abrahams, B. F.; Sorace, L.; Boskovic, C. Dalton Trans. 2010, 39, 4757-4767. (b) Adams, D. M.; Dei, A.; Rheingold A. L.; Hendrickson, D. N. J. Am. Chem. Soc., 1993, 115, 8221-8229. (c) Buchanan, R. M.; Pierpont, C. G. J. Am. Chem. Soc. 1980, 102, 4951-4957.

(8) (a) Poneti, G.; Mannini, M.; Cortigiani, B.; Poggini, L.; Sorace, L.; Otero, E.; Sainctavit, Ph.; Sessoli, R.; Dei, A. Inorg. Chem. 2013, 52, 11798-11805. (b) Alley, K. G.; Poneti, G.; Robinson, P. S. D.; Nafady, A.; Moubaraki, B.; Aitken, J. B.; Drew, S. C.; Ritchie, Ch.; Abrahams, B. F.; Hocking, R. K.; Murray, 
K. S.; Bond, A. M.; Harris, H. H.; Sorace, L.; Boskovic, C. J. Am. Chem. Soc., 2013, 135, 8304-8323. (c) Bin-Salamon, S.; Brewer, S. H.; Depperman, E. C.; Franzen, S.; Kampf, J. W.; Kirk, M. L.; Kumar, R. K.; Lappi, S.; Peariso, K.; Preuss, K. E.; Shultz, D. A. Inorg. Chem. 2oo6, 45, 4461-4467.

(9) (a) Schmidt, R. D.; Shultz, D. A.; Martin, J. D.; Boyle, P. D. J. Am. Chem. Soc. 2010, 132, 6261-6273. (b) Pierpont, C. G. Coord. Chem. Rev. 20o1, 216-217, 99-126. (c) Jung,O. K.; Jo , D. H.; Lee, Y.-A; Conklin, B. J.; Pierpont, C. G. Inorg. Chem., 1997, 36, 19-24.

(10) (a) Yu, F.; Xiang, M.; Wu, Q. G.; He, H.; Cheng, S. -Q.; Cai, X.-y.; Li, A.-h.; Zhang, Y. -m. Inorg. Chim. Acta, 2015, 426, 146-149. (b) Li, B.; Tao, J.; Sun, H.-L.; Sato, O.; Huang, R. -B.; Zheng, L.-S. Chem. Commun. 20o8, 2269-2271. (c) Tao, J.; Maruyama, H.; Sato, O. J. Am. Chem. Soc. 20o6, 128, 17901791.

(11) Adams, D. M.; Dei, A.; Rheingold, A. L.; Hendrickson, D. N. J. Am. Chem. Soc. 1993, 115, 8221-8229.

(12) (a) Chen, L. Q.; Wei, R.; Tao, J.; Huang, R.; Zheng, L. S. Sci. China Chem. 2012, 55, 1037-1041. (b) Attia, A. S.; Pierpont, C. G. Inorg. Chem., 1995, 34, 1172-1179. (c) Cheng, W. Q.; Li, G. L.; Zhang, R.; Ni, Z.-H.; Wang, W. F.; Sato, O. J. Mol. Struct., 2015, 1087, 68.

(13) Li, B.; Chen, L.-Q.; Wei, R.-J.; Tao, J.; Huang, R.-.; Zheng, L. -S. Zheng, Zh. Inog. Chem. 2o11, 5o, 424-426.

(14) Jung, O.-S.; Pierpont, C. G.; J. Am. Chem. Soc. 1994, 116, 2229-2230.

(15) Chen, X. -Y.; Wei, R.-J.; Zheng, L. S.; Tao, J. Inorg. Chem. 2014, 53, 13212-13219.

(16) Novio, F.; Campo, J.; Ruiz-Molina, D. Inorg. Chem., 2014, 53, 8742-8748.

(17) Affronte, M.; Beni, A.; Dei, A.; Sorace, L. Dalton Trans. 2007, 43, 5253-5259.

(18) Bodnar, S. H.; Caneschi, A.; Dei, A.; Shultz, D. A.; Sorace, L. Chem. Commun. 2001, 2150-2151.

(19) (a) Kiriya, D.; Nakamura, K.; Kitagawa, S.; Chang, H.Ch. Chem. Commun., 2o10, 46, 3729-3731. (b) Kiriya, D.; Chang, H.-Ch.; Nakamura, K.; Tanaka, D.; Yoneda, K.; Kitagawa, S. Chem. Mater., 2009, 21, 1980-1988. (c) Kiriya, D.; Chang, H.-Ch.; Kitagawa, S. J. Am. Chem. Soc., 2008, 130, 5515-5522.

(20) (a) Evangelio, E.; Hernando, J.; Imaz, I.; Bardají, G. G.; Alibés, R.; Busqué, F.; Ruiz-Molina, D. Chem. Eur. J. 20o8, 14, 9754-9763. (b) Martínez-Otero, A.; Busqué, F.; Hernando, J.; Ruiz-Molina, D. Nanoscale, 2010,2, 1781-1788.

(21) Guardingo, M.; Bellido, E.; Miralles-Llumà, R.; Faraudo, J.; Sedó, J.; Tatay, S.; Verdaguer, A.; Busqué, F.; Ruiz-Molina, D. Small 2014, 10, 1594-1602.

(22) (a) Imaz, I.; Maspoch, D.; Rodríguez-Blanco, Cl.; PérezFalcón, J. M.; Campo, J.; Ruiz-Molina, D. Angew. Chem. Int. Ed. 2oo8, 47, 1857-186o. (b) Novio, F.; Ruiz-Molina, D. RSC Adv., 2014,4, 15293-15296.

(23) (a) Evangelio, E.; Ruiz-Molina, D. C. R. Chimie, 2oo8, 11, 1137-1154. (b) Evangelio, E.; Rodriguez-Blanco, C.; Coppel, Y.; Hendrickson, D. N.; Sutter, J. P.; Campo, J.; Ruiz-Molina, D. Solid State Sci., 2009, 11, 793-80o.

(24) Lloret, F.; Julve, M.; Cano, J.; Ruiz-García, R.; Pardo, E. Inorg. Chim. Acta 2008, 361, 3432-3445.

(25) Beni, A.; Dei, A.; Shultz, D. A.; Sorace, L. Chem. Phys. Lett. 2006, 428, 400-404.

(26) (a) Novio, F.; Evangelio, E.; Vazquez-Mera, N.; Gonzalez-Monje, P.; Bellido, E.; Mendes, S.; Kehagias, N.; Ruiz-
Molina, D. Sci. Rep. 2013, 3, 1708. (b) Katayama, K.; Hirotsu, M.; Kinoshita, I.; Teki, Y. Dalton Trans., 2014, 43, 13384-13391. (27) Hartl, F.; Barbaro, P.; Bell, I. M.; Clark, R. J. H.; Snoeck, T. L.; Vlček Jr., A. Inorg. Chim. Acta, 1996, 252, 157-166. 


\section{Table of Contents Graphic and Synopsis}

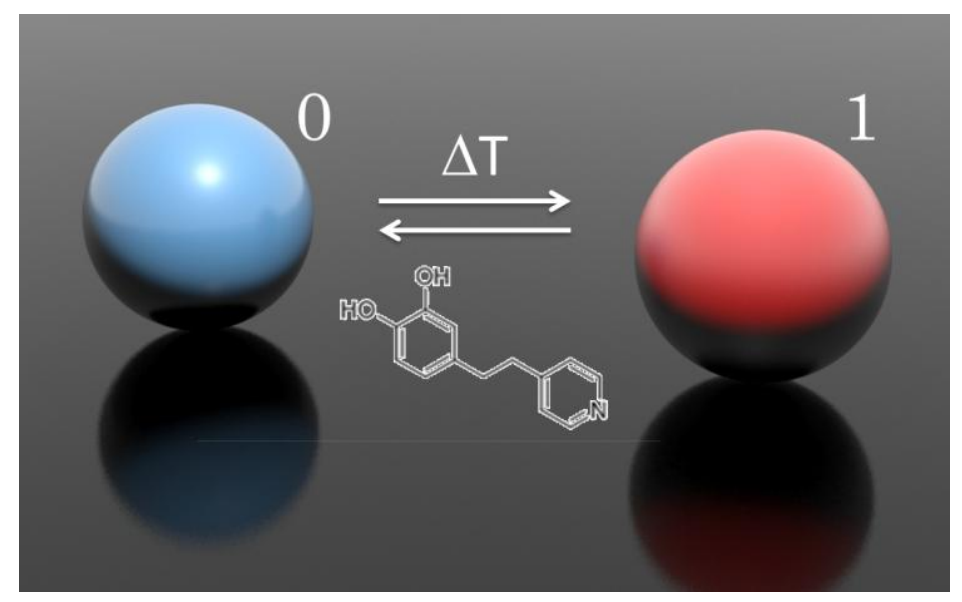

A novel bifunctional ligand L1 combining a redox-active catechol covalently linked to a pyridine unit has been designed and synthesized. The precipitation coordination polymerization of L1 upon reaction with cobalt metal ions leads to the formation of nanoparticles exhibiting a gradual VT interconversion in the 35-370 K temperature range and hysteresis effects. 